\title{
BMJ
}

\section{The relation of price of antiretroviral drugs and foreign assistance with coverage of HIV treatment in Africa: retrospective study}

\author{
Eran Bendavid, assistant professor, ${ }^{1,2}$ Eric Leroux, medical student, ${ }^{3}$ Jay Bhattacharya, associate professor, ${ }^{2,4}$ \\ Nicole Smith, research associate, ${ }^{2}$ Grant Miller, assistant professor ${ }^{2,4}$
}

${ }^{1}$ Division of General Internal Medicine, Stanford University, Stanford, CA 94305, USA

${ }^{2}$ Center for Health Policy and the Center for Primary Care and Outcomes Research, Stanford University

${ }^{3}$ Stanford Medical School, Stanford

${ }^{4}$ National Bureau of Economic Research, Stanford

Correspondence to: E Bendavid ebd@stanford.edu

Cite this as: BMJ 2010;341:c6218 doi:10.1136/bmi.c6218

\section{ABSTRACT}

Objective To determine the association of reductions in price of antiretroviral drugs and foreign assistance for HIV with coverage of antiretroviral treatment.

Design Retrospective study.

Setting Africa.

Participants 13 African countries, 2003-8.

Main outcome measures A price index of first line antiretroviral therapy with data on foreign assistance for HIV was used to estimate the associations of prices and foreign assistance with antiretroviral coverage (percentage of people with advanced HIV infection receiving antiretroviral therapy), controlling for national public health spending, HIV prevalence, governance, and fixed effects for countries and years.

Results Between 2003 and 2008 the annual price of first line antiretroviral therapy decreased from $\$ 1177$ ( $£ 733$; $€ 844)$ to $\$ 96$ and foreign assistance for HIV per capita increased from $\$ 0.4$ to $\$ 13.8$. At an annual price of $\$ 100$, a $\$ 10$ decrease was associated with a $0.16 \%$ adjusted increase in coverage ( $95 \%$ confidence interval $0.11 \%$ to $0.20 \%$; $0.19 \%$ unadjusted, $0.14 \%$ to $0.24 \%$ ). Each additional \$1 per capita in foreign assistance for HIV was associated with a $1.0 \%$ adjusted increase in coverage ( $0.7 \%$ to $1.2 \% ; 1.4 \%$ unadjusted, $1.1 \%$ to $1.6 \%$ ). If the annual price of antiretroviral therapy stayed at $\$ 100$, foreign assistance would need to quadruple to $\$ 64$ per capita to be associated with universal coverage.

Government effectiveness and national public health expenditures were also positively associated with increasing coverage.

Conclusions Reductions in price of antiretroviral drugs were important in broadening coverage of HIV treatment in Africa from 2003 to 2008, but their future role may be limited. Foreign assistance and national public health expenditures for HIV seem more important in expanding future coverage.

\section{INTRODUCTION}

The expansion in coverage of antiretroviral therapy for people infected with HIV in sub-Saharan Africa is both one of the most remarkable accomplishments and a persistent concern in global public health. ${ }^{12}$ At the beginning of the 21 st century, access to antiretroviral therapy was limited in low income countries, but recent estimates suggest that nearly four million infected people in Africa are receiving treatment. ${ }^{3}$ The converging influences of global political support, public-private partnerships, soaring activism, proliferation of non-governmental organisations, and improvements in health service delivery systems for HIV created an environment that enabled exceptional growth in the numbers of people receiving treatment. ${ }^{45}$ Within that milieu, two powerful drivers - drug prices and foreign assistance - directly influenced the quantities of antiretroviral drugs available to infected people in sub-Saharan Africa.

At the turn of the century the price of antiretroviral therapy in Africa was similar to that in developed nations, commonly upwards of $\$ 5000$ ( $£ 3100$; $€ 3600) .{ }^{6}$ Since 2001, prices of antiretroviral drugs have decreased dramatically through a combination of price negotiations, generic pharmaceutical growth, bulk purchasing, and trade agreements. By 2009 the price for a regimen of first line antiretroviral therapy in some places was less than $\$ 100$ a year. ${ }^{7}$ Further reductions in the price of antiretroviral therapy, however, pose a continued challenge as countries are moving towards less toxic but more expensive drugs as preferred treatment. ${ }^{8}$

Concurrently, resources for purchasing antiretroviral drugs in low income countries have increased dramatically since the Declaration of Commitment on HIV/AIDS (adopted by the United Nations General Assembly in 2001). ${ }^{9}$ Three large international organisations accounted for most of the increase in available resources: the President's Emergency Plan for AIDS Relief; the Global Fund to Fight AIDS, Tuberculosis, and Malaria; and the World Bank's Multi-Country HIV/AIDS Program. ${ }^{910}$ The funding for HIV in low and middle income countries - a little over \$1bn in 2000 and over \$15bn in 2008was mostly donated by high income countries, with the United States providing the largest share. ${ }^{1112}$ To date, the largest portion of the funds disbursed through the President's Emergency Plan for AIDS Relief, Global Fund, and World Bank has been used to provide antiretroviral therapy. 
Despite the reductions in price, the increase in foreign assistance, and the enabling environment within which these drivers operated, progress towards achieving universal coverage is currently predicted to fall short of the Millennium Development Goals in many sub-Saharan African countries. ${ }^{11}$

We explore the relations of price reductions of antiretroviral drugs and foreign assistance for HIV with coverage of antiretroviral therapy for three main reasons. Firstly, price reductions and foreign assistance are important policy mechanisms and identifying their role in expanding coverage can help in policy formulation. Secondly, future foreign assistance for $\mathrm{HIV}$ is potentially jeopardised with the global financial crisis and a changing perception that the burden of the HIV epidemic in Africa may be stabilising or decreasing. ${ }^{13}$ Thirdly, price reductions of antiretroviral drugs may stall as current prices approach costs of production and the mix of recommended antiretroviral drugs shifts in favour of more expensive drugs. Understanding these relations provides an important benchmark for planning resources and setting price targets for antiretroviral drugs.

\section{METHODS}

\section{Antiretroviral price index}

We calculated a price index for first line antiretroviral therapy at country and year level for 13 countries in sub-Saharan Africa from 2003 to 2008. Our price data came primarily from the World Health Organization Global Price Reporting Mechanism and the ARNS Economics of AIDS and Access to HIV/ AIDS Care in Developing Countries Project. ${ }^{1415}$ Both sources collected data on prices directly from national AIDS programmes and other major purchasers and published transactional data such as quantities purchased, dosages, and amount paid. We used the price information of each antiretroviral agent in each country and year to calculate a price index, weighted by the quantity and deflated to 2008 US dollars. ${ }^{16}$ We used the current first line formulary in the World Health

\begin{tabular}{|c|c|c|c|}
\hline \multirow[b]{2}{*}{ Variables } & \multicolumn{3}{|c|}{ Mean (SD) } \\
\hline & 2003 & 2005 & 2008 \\
\hline Population (millions) & $32.8(35.0)$ & $34.3(36.7)$ & $36.9(40.2)$ \\
\hline Antiretroviral coverage (\%) & $5.7(4.6)$ & $16.2(15.3)$ & $51.2(23.6)$ \\
\hline Price of first line antiretroviral therapy (2008 \$) & $1177(508)$ & $708(244)$ & $96(18)$ \\
\hline Foreign assistance for HIV per capita $(2008 \$)^{\star}$ & $0.42(0.49)$ & $6.6(8.2)$ & $13.8(16.1)$ \\
\hline HIV prevalence (\%) & $10.1(6.3)$ & $9.6(5.9)$ & $9.3(5.6)$ \\
\hline Public health expenditures per capita (2008 \$)† & $23.7(36.1)$ & $32.5(52.7)$ & $40.9(55.8)$ \\
\hline Public health expenditures (\% of gross domestic product) & $3.1(2.2)$ & $3.2(1.7)$ & $3.4(2.0)$ \\
\hline Living in cities, 2008 (\%) & $30.5(14.8)$ & $31.4(15.1)$ & $32.8(15.5)$ \\
\hline Per capita gross domestic product & $783(1066)$ & $1043(1539)$ & $1306(1673)$ \\
\hline Government effectiveness index $\ddagger$ & $-0.55(0.15)$ & $-0.52(0.19)$ & $-0.47(0.18)$ \\
\hline \multicolumn{4}{|c|}{$\begin{array}{l}\text { *Total resources disbursed for HIV from three major international donors (World Bank, Global Fund, and } \\
\text { President's Emergency Plan for AIDS Relief) per capita. } \\
\text { †Using World Bank's estimates of public health expenditures as percentage of gross domestic product, gross } \\
\text { domestic product, and population to estimate per capita expenditures. } \\
\text { †Raw score from World Bank governance matters index (approximate range }-2.5-2.5 \text { ), with higher scores } \\
\text { reflecting better governance. }\end{array}$} \\
\hline
\end{tabular}

Organization's treatment guidelines to determine the relevant first line drugs. ${ }^{17}{ }^{18}$ Fixed dose combinations of two or three drugs were weighted accordingly. This resulted in a unidimensional (2008 US dollars) price index of first line antiretroviral therapy with observations of country and year.

\section{Foreign assistance to purchase antiretroviral drugs}

The other major economic driver of expanded antiretroviral coverage was foreign assistance to support HIV programmes. We estimated foreign assistance for HIV using public information on disbursements (not commitments) for HIV programmes by the three major international donor organisations: the World Bank, Global Fund, and President's Emergency Plan for AIDS Relief. ${ }^{19-22}$ We used those three organisations as the indicators of foreign support for scaling up antiretroviral therapy in Africa for two main reasons: during the study years most antiretroviral drugs were purchased using funds from one of these sources, and detailed annual data are available from a consistent source. Although other national and private donors also contributed to expanding coverage of antiretroviral therapy in Africa-most notably the United Kingdom's Department for International Development - their contributions have been smaller. ${ }^{23}$

We used data on total disbursements for HIV as opposed to expenditures specific to antiretroviral therapy. Foreign assistance for HIV was used to fund antiretroviral therapy, HIV prevention, care of vulnerable populations, and building capacity for large scale delivery of healthcare to infected people. We used total foreign aid for HIV because the total disbursements were reported over time more consistently and because activities such as treatment, prevention, and care of vulnerable populations often blend and have spill over effects. Foreign assistance was weighted by the population size for each observation of country and year.

\section{Coverage of antiretroviral therapy}

We used published estimates of antiretroviral coverage from the joint United Nations programme on HIV/AIDS (UNAIDS) for each country and year. ${ }^{24-27}$ Coverage is defined as the percentage of adults and children with advanced HIV infection receiving antiretroviral therapy. The number of people receiving antiretroviral therapy is reported by member countries and undergoes a reconciliation process. ${ }^{28-30}$ The estimates of people with advanced HIV come from the UNAIDS reference group on estimates, modelling, and projections, as reported in the epidemiological fact sheets on HIV/AIDS for each country. ${ }^{2731}$

\section{Statistical analysis}

We constructed a panel dataset with annual prices of first line antiretroviral therapy (2008 US dollars), foreign assistance for HIV (2008 US dollars per capita), and antiretroviral coverage (percentage) for the years 2003 to 2008 for all African countries that had complete longitudinal data on price and antiretroviral coverage. The unadjusted analysis examined the 


\section{Time varying covariates that potentially could affect coverage of HIV treatment}

- HIV prevalence-changing burden of disease could have an independent and effect modifying relation with treatment coverage ${ }^{33}$

- Urbanisation-represented as the percentage of the population noted to live in urban areas and is a proxy for ease of access to clinics and healthcare facilities ${ }^{34}$

- Per capita health expenditures-calculated using health expenditures as a percentage of gross domestic productxgross domestic product/population), and explores the contribution of in-country health expenditures to increasing coverage ${ }^{34}$

- Per capita gross domestic product in current US dollars (in purchasing power parity)— a general measure of economic capacity and development status ${ }^{34}$

- Government effectiveness index (using World Bank Governance Matters database)examines whether changes in governance help explain coverage ${ }^{35}$

Thus, the adjusted analysis used a generalised linear model with a normal (Gaussian) link function of the following form:

association between price and foreign assistance as the independent variables and antiretroviral coverage as the dependent variable in a generalised linear model regression. Our adjusted analyses included time varying covariates, a price squared term to allow for a nonlinear relation between price and coverage, and fixed effects for country and year. Country fixed effects control for differences between countries that are constant over time, whereas year fixed effects control for common changes over time. ${ }^{32}$ Our time varying covariates aim to represent the environment within which price reductions and foreign assistance operated and which could have independently affected coverage. These include several epidemiological variables, economic measures, and governance indicators (box).

We used the adjusted model for several calculations. We explored the sensitivity of antiretroviral coverage to changes in price. Because the association of prices and coverage is non-linear (quadratic), coverage is differentially sensitive to changes in price at different price points. We provide estimates of that association at several illustrative price points. We then estimated the increase in coverage explained by price reductions by holding all model inputs other than prices fixed at their 2003 values, and predicted coverage at 2008 . We repeated the analysis for assistance and calculated the portion of the increase in coverage explained by each of these mechanisms. In addition we estimated the resources required for universal coverage at different prices for antiretroviral drugs, levels of foreign assistance, and national public health expenditures. Finally, we calculated the benefits in terms of life years gained using estimates of the health benefits of antiretroviral coverage. All analyses were carried out using Stata software, version 11.

\section{RESULTS}

Thirteen countries with complete information on prices, foreign assistance, and antiretroviral coverage from 2003 to 2008 were studied: Cameroon, Ethiopia, Kenya, Malawi, Mozambique, Namibia, Nigeria, Rwanda, South Africa, Tanzania, Uganda, Zambia, and Zimbabwe. These countries represent about $60 \%$ of Africa's population and 84\% of Africa's estimated number of people living with HIV/AIDS.

In 2003 the mean annual price of first line antiretroviral therapy in the study countries was $\$ 1177$ (SD \$508) per capita and the average coverage of antiretroviral treatment was 5.7\% (SD 4.6\%). By 2008 the mean annual price of first line antiretroviral therapy had decreased to $\$ 96.1$, with substantially less variability (SD \$18.1). During the same period, antiretroviral coverage increased to $51.2 \%$ on average (SD 23.6\%). National public health expenditures per capita increased from $\$ 23.7$ in 2003 to $\$ 40.9$ in 2008 $(\mathrm{P}=0.42)$, although those expenditures were less different when expressed as a percentage of gross domestic product $(3.1 \%$ in 2003 and $3.4 \%$ in $2008, \mathrm{P}=0.75)$. Table 1 shows the descriptive variables of the study countries.

The unadjusted model relating price and foreign assistance to coverage shows a strong association of coverage with both variables. From 2003 to 2008, every $\$ 10$ decrease in the price of first line antiretroviral therapy was associated with a $0.19 \%$ increase in coverage $195 \%$ confidence interval $0.14 \%$ to $0.25 \%$, $\mathrm{P}<0.001)$. Figure 1 shows the association of annual price of first line antiretroviral therapy per capita in 2008 US dollars and antiretroviral coverage. Two important observations are notable: firstly, price reductions were associated with greater increases in antiretroviral coverage at lower prices and, secondly, the annual prices decreased only modestly and converged to a narrow range of prices between 2007 and 2008. The adjusted model includes a non-linear (squared) relation, with price and adjustments for HIV prevalence, per capita national public health expenditures, urban status, per capita gross domestic product, government effectiveness, country fixed effects, and year fixed effects. Using this model, price reductions had a changing association with

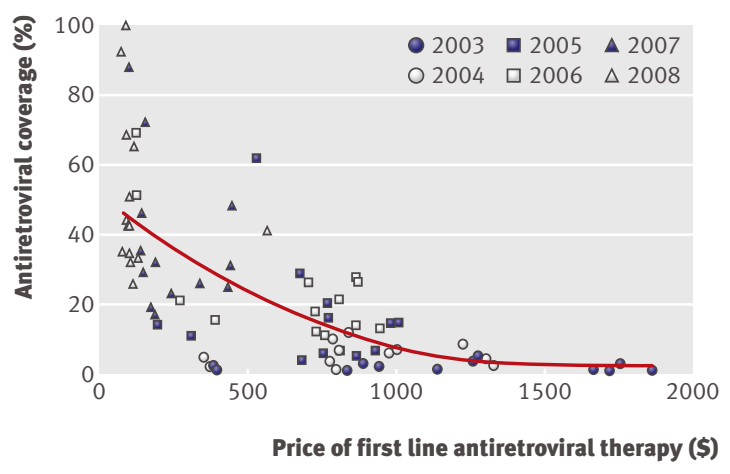

Fig 1| Relation between price of first line antiretroviral therapy and coverage. Points represent country and year estimate of price of therapy in 2008 US dollars and antiretroviral coverage during that year. Markers are differentiated by year of observation to show price trends of therapy. Quadratic fit line suggests greater increases in coverage associated with price reductions at low prices, but coverage averaging just over $50 \%$ with lowest observed prices. In addition, prices appear to converge, so that by 2008 the prices are similar in most countries, suggesting a floor effect for price reductions 
Table 2 Impact of price reductions, foreign assistance, and development and governance indicators on coverage of HIV treatment using antiretroviral drugs in 13 African countries

\begin{tabular}{lcc} 
Variables & $\begin{array}{c}\text { Unadjusted, } \% \\
(95 \% \mathrm{Cl}) \dagger\end{array}$ & $\begin{array}{c}\text { Adjusted, } \% \\
(95 \% \mathrm{Cl}) \ddagger\end{array}$ \\
Reducing price of first line antiretroviral drugs by $\$ 10$ & $\begin{array}{c}0.19(0.14 \text { to } 0.25) \\
\star \star \star\end{array}$ & \\
\hline Annual price $\$ 500$ & & $0.04(0.02 \text { to } 0.06)^{\star \star}$ \\
\hline Annual price $\$ 100$ & $1.4(1.1 \text { to } 1.6)^{\star \star \star}$ & $0.16(0.11 \text { to } 0.20)^{\star \star}$ \\
\hline Increasing foreign assistance per capita by $\$ 1$ & - & $0.7(0.7 \text { to } 1.2)^{\star \star \star}$ \\
\hline$\$ 1$ increase in public health expenditures $\$$ & - & $-2.2(-5.6$ to 1.2$)$ \\
\hline $1 \%$ increase in proportion living in urban areas & - & $1.2(-0.3$ to 2.7$)$ \\
\hline $1 \%$ higher HIV prevalence & - & $-0.4(-0.9$ to 0.1$)$ \\
\hline Per capita gross domestic product higher by $\$ 100$ & - & $0.4(0.1 \text { to } 0.7)^{\star \star}$ \\
\hline Each 1 point increase in government effectiveness $\$$ & &
\end{tabular}

*Significant at $0.05 ;{ }^{* *}$ significant at $0.01 ;{ }^{* * *}$ significant at 0.001

†Unadjusted model includes prices of first line antiretroviral drugs and foreign assistance for HIV expressed in 2008 dollars per capita.

‡Adjusted for HIV prevalence, per capita health expenditures, urban status, per capita gross domestic product, government effectiveness, country fixed effects, and year fixed effects; and includes price squared term to allow non-linear relation with coverage. Country fixed effects control for unobserved country differences that do not vary over time, and year fixed effects control for unmeasured differences that affect countries to same degree over time.

§Measured as overall expenditures for health from national sources in 2008 dollars per capita.

ๆMeasured using World Bank governance matters index.

antiretroviral coverage at different prices. At an annual price of $\$ 500$, every $\$ 10$ decrease in the price of antiretroviral therapy was associated with a $0.04 \%$ increase in coverage $(95 \%$ confidence interval $0.02 \%$ to $0.06 \%$, $\mathrm{P}=0.01$ ), and at an annual price of $\$ 100$, a $\$ 10$ decrease was associated with a $0.16 \%$ increase in coverage $(0.11 \%$ to $0.20 \%, \mathrm{P}=0.01)$.

Foreign assistance for HIV was also closely associated with antiretroviral coverage. Each additional $\$ 1$ per capita in foreign assistance was associated with a $1.4 \%$ increase in antiretroviral coverage $(1.1 \%$ to $1.6 \%, \mathrm{P}<0.001)$ in the unadjusted model and $1.0 \%$ $(0.7 \%$ to $1.2 \%, \mathrm{P}<0.001)$ in the adjusted model. Several adjusters were associated with increased coverage: per capita national public health expenditures, government effectiveness score, and HIV prevalence (nonsignificant trend). Figure 2 shows the association between foreign assistance and coverage, and table 2 shows the associations for the fully adjusted model.

The foreign assistance required for universal coverage was estimated using the adjusted model by holding the values for all covariates other than assistance, fixed at their 2008 levels. Using this approach, at an annual price of $\$ 100$ for first line antiretroviral therapy and current national public health expenditures, foreign assistance for HIV would have to be about $\$ 64$ per capita to reach universal coverage. Among the study countries, only one (Namibia) approaches that level of expenditures. The total assistance required to reach universal coverage in the 13 study countries is estimated at $\$ 14.8 \mathrm{bn}$. At an annual price of $\$ 100$ for first line antiretroviral therapy and foreign assistance for HIV per capita at the 2008 mean $(\$ 13.8)$, the national public health expenditures associated with universal coverage are $\$ 109$ per capita, nearly three times current levels. Figure 3 shows the calculated relation between foreign assistance and national public health expenditures associated with universal coverage at different price points. Price reductions alone without further increase in public health expenditures or foreign assistance for HIV were associated with a maximum coverage of $55.8 \%$ at an annual price of $\$ 1$.

The portion of the increase in coverage explained by prices and assistance was estimated with a thought experiment: if everything remained at 2003 levels except for prices, what would the predicted coverage be in 2008? This was repeated for assistance, and the portion of the predicted increase in coverage with each was calculated. Using this approach prices were estimated to be associated with $20.4 \%$ of the predicted increase in coverage and foreign assistance with $29.1 \%$ of the increase.

Finally, the mortality benefits of price reductions and foreign assistance were calculated. Antiretroviral therapy in sub-Saharan Africa was estimated to prolong life by 4.0-12.1 years, and 4.8 million people were in need of antiretroviral therapy in the 13 study countries in $2006 .{ }^{263637}$ Using the unadjusted model (to avoid non-linear relations), a $\$ 10$ decline in the price of antiretroviral drugs was associated with 36480 110352 years of life saved. Using a similar calculation, each additional $\$ 1$ per capita in foreign assistance for HIV ( $\$ 480 \mathrm{~m}$ for the total study population) was associated with 268800-813120 years of life saved, or $\$ 590-\$ 1784$ per year of life saved.

\section{DISCUSSION}

Our analysis of the relation between price reductions of antiretroviral drugs, foreign assistance for HIV, and the expansion of antiretroviral coverage in 13 African countries sheds light on two of the most important policy mechanisms associated with expanded coverage: price reductions and foreign assistance. The expansion in coverage was closely linked to both between 2003 and 2008. Our estimates suggest that price reductions to even low levels are unlikely to be associated with substantial additional gains in coverage.

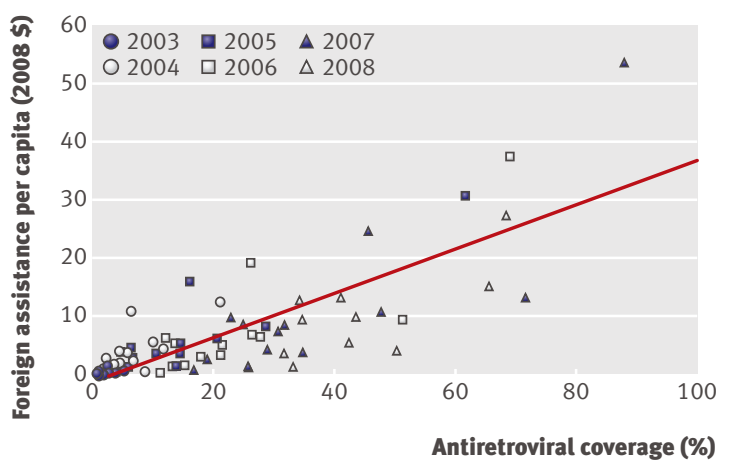

Fig 2 | Relation between foreign assistance and coverage. Foreign assistance is in 2008 US dollars distributed for HIV by three major international donors (President's Emergency Plan for AIDS Relief, Global Fund, and World Bank) per capita in each country during year of interest. Markers are differentiated by year of observation, and quadratic fit curve is shown 


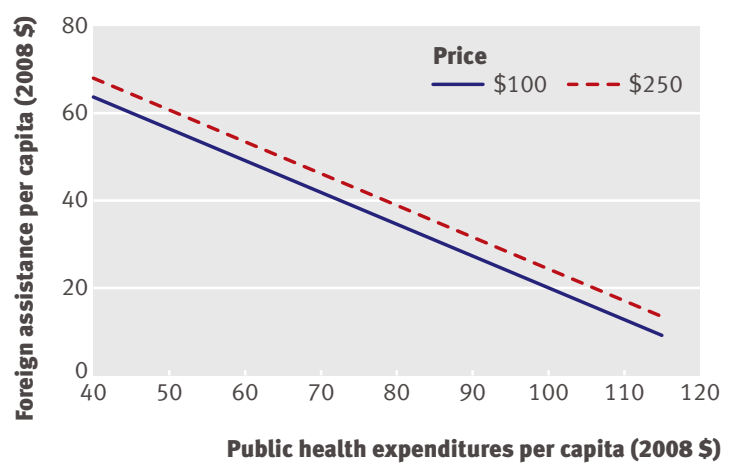

Fig 3| Resource requirements for universal coverage. Combination of foreign assistance for HIV per capita and national public health expenditures estimated to be sufficient for universal coverage at difference price points of first line antiretroviral therapy. As of 2008, public health expenditures in study countries were $\$ 40.9$ per capita and foreign assistance for HIV \$13.8 per capita

Reducing the price of antiretroviral drugs may hold a particular appeal as a policy target for expanding antiretroviral coverage. Price reduction operates through a market mechanism and it may reduce the reliance on uncertain cycles of foreign assistance. However, the effectiveness of price reductions is limited by three important considerations. Firstly, we note that further reductions below the current low prices are unlikely to be associated with universal coverage. Secondly, we note that prices of first line antiretroviral therapy converged around a price that possibly represents something close to the lowest sustainable price. Finally, clinically appropriate considerations are shifting the mix of antiretroviral drugs in use in Africa, raising doubts about future price reductions. High rates of toxicity, increasing use of second line antiretroviral drugs, and difficult dosing schedules of previously recommended antiretroviral regimens are leading to changes in the mix in favour of clinically superior, but also more expensive, drugs.

Understanding the role of price reductions and foreign assistance is pertinent at a time when continued assistance for $\mathrm{HIV}$ is threatened as a result of the global financial crisis. Foreign assistance from governments is often linked to national budgets, and the economic

\section{WHAT IS ALREADY KNOWN ON THIS TOPIC}

The expansion of antiretroviral coverage has been a major accomplishment of the global health community since the turn of the century

This expansion was aided in part by increasing foreign assistance and decreasing prices of antiretroviral drugs

The relations among these drivers of treatment expansion and the contribution of national public health expenditures were, however, not known

\section{WHAT THIS STUDY ADDS}

Prices of antiretroviral drugs and foreign assistance were both closely linked to expanded coverage

Price reductions approach a plateau, however, and may start increasing downturn may have implications for assistance with HIV. Foreign assistance is also threatened by the changing perception of the HIV epidemic. Many successes in increasing assistance for HIV occurred in response to the perception of HIV as a humanitarian, diplomatic, security, and development crisis in Africa. ${ }^{38}$ As the epidemic is stabilising in many parts of subSaharan Africa, that perception is changing. ${ }^{39}$ Our analysis shows, however, that if universal coverage is a sought after goal, foreign assistance and national public health expenditures should increase substantially, especially as the criteria for initiating antiretroviral therapy are liberalised. ${ }^{40}$

\section{Limitations of the study}

Several limitations are important to note. We used contributions for HIV from the World Bank, Global Fund, and President's Emergency Plan for AIDS Relief to measure foreign assistance for HIV. Although these organisations provide the largest share of the available funds for purchasing antiretroviral drugs, this measure is limited in two ways. Firstly, it does not take into account the proliferation in contributions and activities from non-governmental organisations, which occurred over the same period. Secondly, we lumped all assistance for HIV together without accounting for the different activities supported by HIV funding, such as prevention, education, and strengthening of the health system.

Our price index is limited in estimating the true price of antiretroviral therapy. As the prices of antiretroviral drugs decrease, the costs of delivering therapy, such as laboratory monitoring, supply chain, and human resources are taking an ever greater role. In addition, the transactional prices we collected do not represent the price at the point of care, and our analysis is most relevant at a societal level. We focused on the price of first line antiretroviral drugs and did not include more expensive first or second line drugs; however, the increasing use of more expensive drugs underscores the possible future role of price reductions. Finally, many of our calculations rely on extrapolations of the data from 2003 to 2008, and our estimates therefore assume stable relations among the various factors contributing to antiretroviral coverage.

\section{Policy implications}

We provide the first exploration on the relation between price of first line antiretroviral therapy, foreign assistance for HIV, and antiretroviral coverage, and suggest that further price reductions have a limited potential in further expanding antiretroviral coverage. Rather, further expansion will depend almost entirely on increasing expenditures from foreign donors or domestic sources.

We thank Kanaka Shetty of RAND (Research ANd Development) for insightful comments.

Contributors: EB analysed the data and wrote the manuscript. EL collected the data and was involved in critical revisions. JB was involved in conceptualising and formulating the principal issues. NS collected and synthesised the price data. GM obtained the data, formulated the concept, and was involved in critical revisions. EB had full access to all of 
the data in the study and takes responsibility for the integrity of the data and the accuracy of the data analysis. EB is guarantor. Funding: EB is supported by the National Institute of Allergy and Infectious Diseases (K01-AI084582). GM and JB receive support from the National Institute of Child Health and Development. All three receive support from the National Institute of Aging and the Center on the Demography and Economics of Health and Aging (P30-AG17253) Competing interests: All authors have completed the Unified Competing Interest form at www.icmje.org/coi_disclosure.pdf (available on request from the corresponding author) and declare: no support from any company for the submitted work; no financial relationships with any companies that might have an interest in the submitted work in the previous 3 years; no other relationships or activities that could appear to have influenced the submitted work.

Ethical approval: This study was determined to be of non-human participation by the institutional review board at Stanford University. Data sharing: Analytical dataset available on request from corresponding author at ebd@stanford.edu.

1 World Health Organization. The 3 by 5 Initiative. 2009. www.who.int/ 3by $5 /$ en/.

2 The Copenhagen Consensus Center. 2008. www. copenhagenconsensus.com/The $\% 2010 \% 20$ challenges/Diseases. aspx.

3 World Health Organization. More than five million people receiving HIV treatment. 2010. www.who.int/mediacentre/news/releases/ 2010/hiv treament 20100719/en/index.html.

4 Kumarasamy N. Generic antiretroviral drugs-will they be the answer to HIV in the developing world? Lancet 2004;364:3-4.

5 Kober K, Van Damme W. Scaling up access to antiretroviral treatment in southern Africa: who will do the job? Lancet 2004;364:103-7.

6 Baleta A. Cautious welcome for antiretroviral cost reduction in South Africa. Lancet 2000;355:1799.

7 Medicins Sans Frontieres. Untangling the web of antiretroviral price reductions. 2010. http://utw.msfaccess.org/downloads.

8 World Health Organization. Rapid advice: antiretroviral therapy for HIV infection in adults and adolescents. 2009. WHO.

9 UNAIDS. Report on the Global AIDS epidemic. Joint United Nations Programme on HIV/AIDS; 2008.

10 AVERT. Where does AIDS funding come from? 2009. www.avert.org/ aids-funding.htm.

11 UNAIDS. Financial resources required to achieve universal access to HIV prevention, treatment, care and support. UNAIDS; 2007.

12 UNAIDS and Kaiser Family Foundation. Financing the response to AIDS in low- and middle income countries: international assistance from the G8, European Commission and other donor governments in 2009. www.kff.org/hivaids/upload/7347-06.pdf.

13 McNeil D. At front lines, AIDS war is falling apart. New York Times May 9, 2010.

14 Lucchini S, Cisse B, Duran S, Cenival M, Moatti J. Decrease in prices of antiretroviral drugs for developing countries: from political "philantropy" to regulated markets? In: Moatti J, Coriat B, Barnett T, Flori Y, eds. Economics of AIDS and access to HIV-care issues and challenges for developing countries. ANRS, Collection Sciences Sociales et Sida; 2003.

15 World Health Organization: Global price reporting mechanism. 2009. www.who.int/hiv/amds/gprm/en/.

16 Bureau of Economic Analysis. Implicit price deflators for gross domestic product. 2008. www.bea.gov.

17 World Health Organization. Antiretroviral therapy for HIV infection in adults and adolescents: recommendations for a public health approach (2006 revision). WHO.
18 World Health Organization. Scaling up antiretroviral therapy in resource-limited settings: treatment guidelines for a public health approach (2003 revision). WHO.

19 AVERT. PEPFAR funding: how is the money spent? 2009. www.avert. org/pepfar-funding.htm.

20 The US President's Emergency Plan for AIDS Relief (PEPFAR)—fiscal year 2009: PEPFAR operational plan. 2009. www.pepfar.gov/ documents/organization/124050.pdf.

21 The Global Fund. Pledges \& contributions. 2010. www. theglobalfund.org/en/pledges/.

22 The World Bank: Multi-Country HIV/AIDS Program (MAP): approved HIV/AIDS projects by FY, total financing and disbursements. 2010. http://siteresources.worldbank.org/INTHIVAIDS/Resources/ HIVAIDSCommitmentsDisbursements)uly212009.xls.

23 OECD Statistics Database. Creditor reporting system. 2010. http:// stats.oecd.org/Index.aspx?DatasetCode=CRSNEW.

24 UNAIDS/WHO. Towards universal access: scaling up priority HIV/ AIDS interventions in the health sector. Progress report. UNAIDS/ WHO; 2009.

25 UNAIDS/WHO. Towards universal access: scaling up priority HIV/ AIDS interventions in the health sector. Progress report. UNAIDS/ WHO; 2008

26 UNAIDS. Towards universal access: scaling up priority HIV/AIDS interventions in the health sector. Progress report. UNAIDS/WHO; 2007.

27 Epidemiological fact sheet on HIV/AIDS and sexually transmitted infections, 2004 update for member countries. 2009. http://data. unaids.org/Publications/Fact-Sheets01.

28 Walker N, Grassly NC, Garnett GP, Stanecki KA, Ghys PD. Estimating the global burden of HIV/AIDS: what do we really know about the HIV pandemic? Lancet 2004;363:2180-5.

29 Ghys PD, Walker N, McFarland W, Miller R, Garnett GP. Improved data, methods and tools for the 2007 HIV and AIDS estimates and projections. Sex Transm Infect 2008;84(suppl 1):i1-4.

30 Stover J, Walker N, Grassly NC, Marston M. Projecting the demographic impact of AIDS and the number of people in need of treatment: updates to the Spectrum projection package. Sex Transm Infect 2006;82(suppl 3):iii45-50.

31 Epidemiological fact sheet on HIV and AIDS, 2008 update fo member countries. 2009. www.who.int/hiv/pub/epidemiology/ pubfacts/en/.

32 Stock J, Watson M. Introduction to econometrics: Addison Wesley; 2003.

33 UNAIDS. 2008 Report on the global AIDS epidemic. Epidemiology information, 2008. 2009. www.unaids.org/en/KnowledgeCentre/ HIVData/GlobalReport/2008/2008_Global_report.asp.

34 The World Bank. World development indicators. 2010. http://data. worldbank.org/data-catalog/world-development-indicators.

35 The World Bank. Governance matters: worldwide governance indicators. 2010. http://info.worldbank.org/governance/wgi/index. asp.

36 Goldie SJ, Yazdanpanah Y, Losina E, Weinstein MC, Anglaret X, $\mathrm{Hsu} \mathrm{HE}$, et al. Cost-effectiveness of HIV treatment in resource-poor settings-the case of Cote d'Ivoire. N Engl J Med 2006;355:1141-53.

37 Bender M, Kumarasamy N, Mayer K, Wang B, Walensky RP, Flanigan T, et al. Cost-effectiveness of tenofovir as first-line antiretroviral therapy in India. Clin Infect Dis 2010;50:416-25.

38 United Nations. Declaration of commitment on HIV/AIDS. Resolution adopted by the General Assembly, August 2, 2001. 2009. www.un. org/ga/aids/docs/aress262.pdf.

39 El-Sadr WM, Hoos D. The President's Emergency Plan for AIDS Relief -is the emergency over? N Engl/ Med 2008;359:553-5.

40 Walensky R, Wolf L, Wood R, Fofana M, Freedberg K, Martinson N, et al. When to start antiretroviral therapy in resource-limited settings. Ann Intern Med 2009;151:157-66.

Accepted: 14 September 2010 